\title{
Metal-Organic Frameworks Constructed from Group 1 Metals (Li, Na) and Silicon-Centered Linkers
}

\author{
David Pugh, ${ }^{\text {a }}$ Emma Ashworth, ${ }^{\text {a }}$ Karen Robertson, ${ }^{\text {a }}$ Luke C. Delmas, ${ }^{\text {a }}$ Andrew J. P. White, ${ }^{a}$ \\ Peter N. Horton, ${ }^{\mathrm{b}}$ Graham J. Tizzard, ${ }^{\mathrm{b}}$ Simon J. Coles, ${ }^{\mathrm{b}}$ Paul D. Lickiss, ${ }^{* \mathrm{a}}$ and Robert P. \\ Davies*a
}

a: Molecular Sciences Research Hub, Imperial College London, 80 Wood Lane, London, W12 0BZ, UK

b: National Crystallography Service, Chemistry, University of Southampton, Highfield, Southampton, SO17 1BJ, UK

$$
\begin{aligned}
& \text { Tel.: +44 (0) } 207594 \text { 5761; e-mailp.lickiss@imperial.ac.uk (PDL) } \\
& \text { Tel.: +44 (0)20 } 7594 \text { 5754; e-mail r.davies@imperial.ac.uk (RPD) }
\end{aligned}
$$

\begin{abstract}
A series of 'light metal' MOFs containing SBUs based on $\mathrm{Li}^{+}$and $\mathrm{Na}^{+}$cations have been prepared using the silicon-centered linkers $\mathrm{Me}_{\mathrm{x}} \mathrm{Si}\left(p-\mathrm{C}_{6} \mathrm{H}_{4} \mathrm{CO}_{2} \mathrm{H}\right)_{4-\mathrm{x}}(\mathrm{x}=2,1,0)$. The unipositive charge, small size, and oxophilic nature of the metal cations gives rise to some unusual and unique secondary building units (SBUs), including a 3D nodal structure built from sodium and oxygen ions when using the triacid linker $(\mathrm{x}=1)$. The same linker with $\mathrm{Li}^{+}$ cations generated a chiral, helical SBU, formed from achiral starting materials. 1D rod SBUs are observed for the diacid $(\mathrm{x}=2)$ and tetra-acid $(\mathrm{x}=0)$ linkers with both $\mathrm{Li}^{+}$and $\mathrm{Na}^{+}$ cations, where the larger size of $\mathrm{Na}^{+}$compared to $\mathrm{Li}^{+}$leads to subtle differences in the constitution of the metal nodes.
\end{abstract}

\section{Introduction}

The use of metal organic frameworks (MOFs) in areas as diverse as gas separation, heterogeneous catalysis, and drug delivery has grown exponentially in recent years. ${ }^{1-4}$ Designer porous solids like MOFs can possess properties such as extremely high surface area and low density, making them ideal candidates for "portable" gas storage applications such as $\mathrm{H}_{2} / \mathrm{CH}_{4}$ fuel tanks for automotive applications. ${ }^{5-8}$ Maximizing the volumetric and gravimetric capacities is crucial for these applications, and one approach is to use lighter elements such as $\mathrm{Li}^{+}, \mathrm{Na}^{+}, \mathrm{Mg}^{2+}$, or $\mathrm{Al}^{3+}$ as the metal nodes in MOFs.

Although a small number of coordination polymers with $\mathrm{Li}^{+}$-based nodes had previously appeared in the wider literature, ${ }^{9}$ the first $\mathrm{Li}^{+}$-based MOF showing permanent porosity was not reported until 2010 by Abrahams et al. using an anionic isonicotinate linker to give a porous MOF which demonstrated modest $\mathrm{H}_{2}$ uptake. ${ }^{10}$ Since then, $\mathrm{Li}^{+}$-based MOFs have been reported using linkers as varied as amino acids, thiophenedicarboxylates, and anthraquinones. ${ }^{11-16}$ These $\mathrm{Li}^{+}$-based MOFs have been shown to display properties such as luminescence, ${ }^{17-19}$ gas uptake, ${ }^{20-21}$ and even have potential applications as electrodes in Li 
batteries. ${ }^{13}$ Some $\mathrm{Na}^{+}$-based MOFs have also been reported to possess similar properties to their $\mathrm{Li}^{+}$analogs such as gas sorption, luminescence, and anodes for $\mathrm{Na}$ batteries. ${ }^{22-24}$ Despite this, $\mathrm{Na}^{+}$-based MOFs have been less well studied, partly because the larger cation size results in increased coordination to polar solvents which favors low dimensional coordination networks. ${ }^{9}$ Therefore, our understanding of the properties and applications of MOFs based on s-block metals lags significantly behind that of MOFs based on d-block metals.

We have previously reported a series of polycarboxylic acids based around a tetrahedral silicon center $\left(\mathbf{L} 1-\mathbf{H}_{2}, \mathbf{L} 2-\mathbf{H}_{3}, \mathbf{L} 3-\mathbf{H}_{4}\right.$; Figure 1) which were used to construct MOFs with $\mathrm{Zn}^{2+}$-based nodes. ${ }^{25}$ The potential for generating novel 3D structural motifs is much higher with a tetrahedral center compared to a planar linker; and using silicon instead of carbon has several advantages including a straightforward linker synthesis. Despite this, only a handful of MOFs have been synthesized using $\mathbf{L 1}$ and $\mathbf{L 2} .^{26-28} \mathbf{L 3}$ has been used to synthesize MOFs with a variety of d-block, ${ }^{29-32}$ and f-block metal nodes, ${ }^{33-36}$ but the only MOFs with s-block metal nodes were reported by us using $\mathrm{Mg}^{2+}$ or $\mathrm{Ca}^{2+} \cdot{ }^{37}$ Latterly, Moon and co-workers reported the synthesis of a MOF with $\mathbf{L 3}$ as linker and $\mathrm{Li}^{+}$-based nodes which was used as a precursor to porous lithium orthosilicate. ${ }^{38}$ Herein we report a series of novel $\mathrm{Li}^{+}$and $\mathrm{Na}^{+}$ MOFs using L1, L2, and $\mathbf{L 3}$ as linkers which exhibit a variety of unusual structural motifs and topologies.

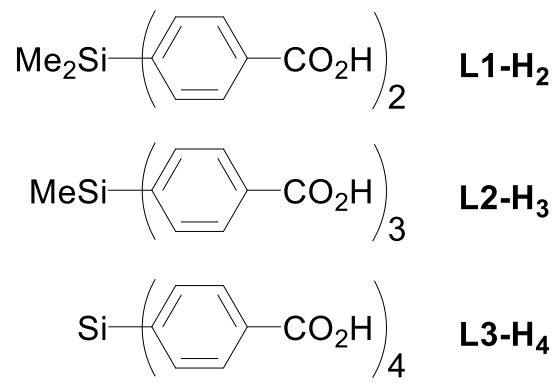

Figure 1: Silicon-centered linkers L1-H2, L2-H3, and L3-H4.

\section{Experimental}

1,4-Dibromobenzene, ${ }^{\mathrm{n}} \mathrm{BuLi}$ (2.5 $\mathrm{M}$ solution in hexanes), and $\mathrm{SiCl}_{4}$ were purchased from Sigma; $\mathrm{SiMe}_{2} \mathrm{Cl}_{2}$ and $\mathrm{SiMeCl}_{3}$ were purchased from Fluka; $\mathrm{CO}_{2}$ was purchased from $\mathrm{BOC}$; $\mathrm{LiNO}_{3}, \mathrm{NaNO}_{3}$, and $\mathrm{LiOH} \cdot \mathrm{H}_{2} \mathrm{O}$ were purchased from Acros: all were used without further purification. Solvents for reactions involving ${ }^{\mathrm{n}} \mathrm{BuLi}$ were dried using a Grubbs-type solvent purification system. The proligands $\operatorname{SiMe}_{\mathrm{x}}\left(\mathrm{p}-\mathrm{C}_{6} \mathrm{H}_{4} \mathrm{CO}_{2} \mathrm{H}\right)_{4-\mathrm{x}}\left(\mathrm{x}=2, \mathbf{L} \mathbf{1}-\mathbf{H}_{2} ; \mathrm{x}=1, \mathbf{L} \mathbf{2}-\mathbf{H}_{3} ; \mathrm{x}=\right.$ $\left.0, \mathbf{L 3}-\mathbf{H}_{4}\right)$ were synthesized according to literature procedures.

Infra-red spectra were obtained on a Perkin Elmer Spectrum 100 with a universal ATR sampling accessory. TGA was carried out on a Perkin Elmer Pyris 1 instrument under a nitrogen atmosphere over the range $50-600{ }^{\circ} \mathrm{C}$ at a heating rate of $10{ }^{\circ} \mathrm{C} / \mathrm{min}$. Elemental analysis was carried out by Stephen Boyer at London Metropolitan University.

Powder X-ray diffraction (PXRD) studies were performed using a Panalytical MPD X-ray diffractometer with $\mathrm{Cu}-\mathrm{K}_{\alpha}$ radiation between 5 and $50^{\circ} 2 \Theta$. Brunauer-Emmet-Teller (BET) analysis was carried out on a Micromeritics TriStar II PLUS and the software used to calculate the surface area was 'Micromeritics MicroActive for TriStar II PLUS'. 
IMP-22: $\left[\mathrm{Li}_{4}(\mathbf{L 1})_{2}\left(\mathrm{H}_{2} \mathrm{O}\right)(\mathrm{DMF})_{2}\right]$

$\mathrm{LiNO}_{3}(42 \mathrm{mg}, 0.60 \mathrm{mmol}), \mathrm{LiOH} \cdot \mathrm{H}_{2} \mathrm{O}(25 \mathrm{mg}, 0.60 \mathrm{mmol}), \mathbf{L 1}-\mathrm{H}_{2}(181 \mathrm{mg}, 0.60 \mathrm{mmol})$, and a 2:1 DMF:MeOH mixture $(15 \mathrm{~mL})$ were stirred for $2 \mathrm{~h}$ at room temperature and then heated to $180{ }^{\circ} \mathrm{C}$ in an autoclave for 5 days. The reaction was cooled slowly to room temperature, affording colorless rod-like crystals which were isolated by filtration, washed with DMF (3 x $1 \mathrm{~mL})$, and air-dried for 1 hour. Yield: $156 \mathrm{mg}(52 \%)$.

Anal. calc. for $\left[\mathrm{Li}_{4}\left\{\mathrm{Me}_{2} \mathrm{Si}\left(\mathrm{C}_{6} \mathrm{H}_{4} \mathrm{CO}_{2}\right)_{2}\right\}_{2}\left(\mathrm{H}_{2} \mathrm{O}\right)(\mathrm{DMF})_{2}\right]$ : C, 55.98; H, 6.50; N, 6.95. Found: $\mathrm{C}$, 56.07; H, 6.40; N, 7.00.

IR: 2956, 1660, 1591, 1541, 1498, 1392, 1310, 1247, 1147, 1101, 1062, 827, 812, 776, 761, $721,660 \mathrm{~cm}^{-1}$.

\section{IMP-23: $\left[\mathrm{Na}_{2}(\mathbf{L 1})(\mathrm{DMF})_{2}\right]$}

$\mathrm{NaNO}_{3}(28 \mathrm{mg}, 0.33 \mathrm{mmol})$ and $\mathbf{L 1}-\mathbf{H}_{2}(50 \mathrm{mg}, 0.17 \mathrm{mmol})$ were dissolved in DMF (2 mL) in a sealed $25 \mathrm{~mL}$ pressure vessel. The solution was heated to $170{ }^{\circ} \mathrm{C}$ for $120 \mathrm{~h}$, then cooled to RT over $6 \mathrm{~h}$. Colorless needle-like crystals were isolated by filtration, washed with DMF $(3 \times 1 \mathrm{~mL})$ and air-dried for 1 hour. Yield: $26 \mathrm{mg}$ (31\%).

Anal. calc. for $\left[\mathrm{Na}_{2}\left(\mathrm{Me}_{2} \mathrm{Si}\left(\mathrm{C}_{6} \mathrm{H}_{4} \mathrm{CO}_{2}\right)_{2}\right)(\mathrm{DMF})_{1.1}\left(\mathrm{H}_{2} \mathrm{O}\right)_{6.1}\right]: \mathrm{C}, 43.35 ; \mathrm{H}, 6.39 ; \mathrm{N}, 2.88$. Found: C, 42.95; H, 5.85; N, 3.26. Note: the elemental analysis is consistent with partial loss of the DMF/water which was located in the channels of IMP-23.

IR: $1653,1587,1534,1388,1256,1245,1141,1096,1064,1019,831,816,777,765,723$, $706,662 \mathrm{~cm}^{-1}$.

\section{IMP-24: [Li3 $(\mathbf{L 2})(\mathrm{DMF})]$}

$\mathrm{LiNO}_{3}(25 \mathrm{mg}, 0.37 \mathrm{mmol}), \mathbf{L} 2-\mathbf{H}_{3}(50 \mathrm{mg}, 0.12 \mathrm{mmol})$, and DMF (2 mL) were stirred for 2 $\mathrm{h}$ at room temperature and then heated to $170{ }^{\circ} \mathrm{C}$ in a screw-top vial for 5 days. The reaction was cooled slowly to room temperature, yielding colorless rod-shaped crystals which were isolated by filtration, washed with DMF (3 x $1 \mathrm{~mL})$, and air-dried for 1 hour. Yield: $51 \mathrm{mg}$ $(81 \%)$.

Anal. calc. for $\left[\mathrm{Li}_{3} \mathrm{MeSi}\left(\mathrm{C}_{6} \mathrm{H}_{4} \mathrm{CO}_{2}\right)_{3}(\mathrm{DMF})\right]$ : C, 60.08; H, 4.58; N, 3.21. Found: $\mathrm{C}, 59.87 ; \mathrm{H}$, $4.49 ; \mathrm{N}, 3.26$.

IR: 2937, 2166, 1948, 1671, 1607, 1542, 1498, 1392, 1308, 1257, 1189, 1147, 1102, 1020, $967,855,790,764,740,717,707,671 \mathrm{~cm}^{-1}$.

IMP-25: $\left[\mathrm{Na}_{12}(\mathbf{L 2})_{4}(\mathrm{DMF})_{3}\right]$ and $\underline{\mathbf{I M P}-26}:\left[\mathrm{Na}_{42}(\mathbf{L 2})_{14}\left(\mathrm{H}_{2} \mathrm{O}\right)_{3}\right]$

$\mathrm{NaNO}_{3}(31 \mathrm{mg}, 0.37 \mathrm{mmol})$ and $\mathbf{L} 2-\mathbf{H}_{3}(50 \mathrm{mg}, 0.12 \mathrm{mmol})$ were suspended in DMF (2 mL). The mixture was heated in a sealed $25 \mathrm{~mL}$ pressure vessel at $170{ }^{\circ} \mathrm{C}$ for $120 \mathrm{~h}$, then cooled to room temperature over a period of $6 \mathrm{~h}$. Two morphologies of colorless crystals had formed: rhombohedra (IMP-25) and needles (IMP-26), in a roughly 1:2 ratio. The mixture of crystals 
was isolated by filtration, washed with DMF, hexane, and methanol, then dried in vacuo. Combined yield of IMP-24 and IMP-25: 5 mg.

IR: $1667,1582,1534,1497,1392,1248,1100,1017,848,793,765,737,720,708,667 \mathrm{~cm}^{-1}$.

Note: since IMP-24 and IMP-25 could only be prepared as a mixture it was not possible to obtain a satisfactory elemental analysis.

\section{IMP-27Li: $\left[\mathrm{Li}_{4}(\mathbf{L 3})(\mathrm{DMF})\left(\mathrm{H}_{2} \mathrm{O}\right)_{2}\right]$}

$\mathrm{LiNO}_{3}(27 \mathrm{mg}, 0.39 \mathrm{mmol}), \mathbf{L 3}-\mathrm{H}_{4}(50 \mathrm{mg}, 0.10 \mathrm{mmol})$, and DMF (2 mL) were stirred for 2 $\mathrm{h}$ at room temperature and then heated to $170{ }^{\circ} \mathrm{C}$ in a screw-top vial for 5 days. Slow cooling to room temperature afforded colorless crystals. These were isolated by filtration, washed with DMF (3 x $1 \mathrm{~mL})$, and air-dried for 1 hour. Yield: $36 \mathrm{mg}(28 \%)$.

Anal. calc. for $\left[\mathrm{Li}_{4}\left\{\mathrm{Si}\left(\mathrm{C}_{6} \mathrm{H}_{4} \mathrm{CO}_{2}\right)_{4}\right\}(\mathrm{DMF})\left(\mathrm{H}_{2} \mathrm{O}\right)_{2}\right] \cdot 7 \mathrm{DMF} \cdot 8 \mathrm{H}_{2} \mathrm{O}: \mathrm{C}, 48.50 ; \mathrm{H}, 6.10 ; \mathrm{N}, 8.58$ \%. Found: C, 48.49; H, 6.38; N, 8.59\%. Note: the elemental analysis is a good fit for $7 \mathrm{DMF}$ and 8 water molecules being located in the channels of IMP-27Li, but a combination of twinned crystals and disorder prevented unambiguous assignment of this crystallographically. See ESI for further details.

IR: 2859, 1581, 1532, 1384, 1097, 1018, 862, 777, 726, 633, 551, 522, $475 \mathrm{~cm}^{-1}$.

\section{IMP-27Na: $\left[\mathrm{Na}_{4}(\mathbf{L 3})(\mathrm{DMF})_{4}\left(\mathrm{H}_{2} \mathrm{O}\right)_{4}\right]$}

$\mathrm{NaNO}_{3}$ (33 mg, $\left.0.39 \mathrm{mmol}\right), \mathbf{L 3}-\mathrm{H}_{4}(50 \mathrm{mg}, 0.10 \mathrm{mmol})$, and DMF (2 mL) were stirred for 2 $\mathrm{h}$ at room temperature, then heated to $170{ }^{\circ} \mathrm{C}$ in a screw-top vial for 5 days. Slow cooling to room temperature yielded colorless prisms which were isolated by filtration, washed with DMF ( $3 \times 1 \mathrm{~mL})$, and air-dried for 1 hour. Yield: $21 \mathrm{mg}(24 \%)$.

Anal. calc. for $\left[\mathrm{Na}_{4}\left\{\mathrm{Si}\left(\mathrm{C}_{6} \mathrm{H}_{4} \mathrm{CO}_{2}\right)_{4}\right\}(\mathrm{DMF})_{5}\left(\mathrm{H}_{2} \mathrm{O}\right)_{8}\right]$ : C, 46.51; H, 6.09; N, 6.31. Found: $\mathrm{C}$, $46.16 ; \mathrm{H}, 6.28 ; \mathrm{N}, 6.15$. Note: elemental analysis is consistent with additional DMF and water present in the channels of the MOF.

IR: 2927, 1666, 1606, 1542, 1494, 1440, 1386, 1281, 1253, 1095, 1018, 846, 814, 769, 722, $707,663,634,548,505 \mathrm{~cm}^{-1}$.

X-Ray crystallography: Datasets were collected using the following hardware: IMP-22: an Oxford Diffraction PX Ultra diffractometer $\left(\mathrm{Cu} \mathrm{K}_{\alpha}\right.$ radiation, $\left.1.54184 \AA\right)$; IMP-23: a Rigaku FRE+ diffractometer (Mo $\mathrm{K}_{\alpha}$ radiation, $0.71073 \AA$ ) equipped with HF Varimax confocal mirrors, an AFC12 goniometer, HG Saturn 724+ detector, and an Oxford Cryosystems lowtemperature device; L1-H2, IMP-24, and IMP-25: an Oxford Diffraction Xcalibur 3E (Mo $\mathrm{K}_{\alpha}$ radiation, $0.71073 \AA$ ); IMP-26: a Rigaku 007HF equipped with Varimax confocal mirrors $\left(\mathrm{Cu} \mathrm{K} \mathrm{K}_{\alpha}\right.$ radiation, $1.54184 \AA$ ), an AFC11 goniometer, and HyPix 6000 detector diffractometer equipped with an Oxford Cryosystems low-temperature device. Datasets were processed using CrysAlisPro, ${ }^{40}$ solutions were solved and refined using SHELX-97 and SHELXTL, ${ }^{41}$ as well as Olex-2, ${ }^{42}$ and WinGX. ${ }^{43}$ 
The dataset for IMP-27Na was collected at the Diamond Light Source using synchrotron radiation $(0.68890 \AA)$ on a Nonius KappaCCD area detector using $\varphi$ and $\omega$ scans to fill the asymmetric unit sphere. The unit cell was determined using DirAx ${ }^{44}$ data collection used Collect, ${ }^{45}$ data reduction and cell refinement used Denzo, ${ }^{46}$ and the absorption correction was carried out with SADABS. ${ }^{47}$ Structure solution was carried out using SHELXS-97 and refinement used SHELXL-97.

The SQUEEZE routine within PLATON was used to remove heavily disordered solvents from the MOF structures. ${ }^{48}$ Graphics were generated using ORTEP-III ${ }^{43}$ and Crystalmaker. ${ }^{49}$ The program enCIFer was used to prepare CIFs for publication. ${ }^{50}$ CCDC reference numbers 1573356 (IMP-22), 1573357 (IMP-24), 1871441 (L1-H2), 1871442 (IMP-27Na), 1871443 (IMP-23), 1871444 (IMP-25) and 1871445 (IMP-26) contain crystallographic data in CIF format, which is summarized below (Table 1).

\begin{tabular}{|c|c|c|c|c|c|c|c|}
\hline Compound & L1-H & IMP-22 & IMP-23 & IMP-24 & IMP-25 & IMP-26 & IMP27-Na \\
\hline Formula & $\mathrm{C}_{16} \mathrm{H}_{16} \mathrm{O}_{4} \mathrm{Si}$ & $\begin{array}{l}\mathrm{C}_{38} \mathrm{H}_{44} \mathrm{Li}_{4} \mathrm{~N}_{2} \mathrm{O}_{11} \mathrm{~S} \\
\mathrm{i}_{2} \cdot 2.5\left(\mathrm{C}_{3} \mathrm{H}_{7} \mathrm{NO}\right)\end{array}$ & $\begin{array}{l}\mathrm{C}_{23.5} \mathrm{H}_{31.5} \mathrm{~N}_{2 .} \\
{ }_{5} \mathrm{Na}_{2} \mathrm{O}_{6.5} \mathrm{Si}\end{array}$ & $\begin{array}{l}\mathrm{C}_{25} \mathrm{H}_{22} \mathrm{Li}_{3} \mathrm{NO}_{7} \mathrm{Si} \\
.2 / 5\left(\mathrm{C}_{3} \mathrm{H}_{7} \mathrm{NO}\right)\end{array}$ & $\begin{array}{l}\mathrm{C}_{32.33} \mathrm{H}_{27} \mathrm{NN} \\
\mathrm{a}_{4} \mathrm{O}_{9} \mathrm{Si}_{1.33}\end{array}$ & $\begin{array}{l}\mathrm{C}_{308} \mathrm{H}_{216} \mathrm{~N} \\
\mathrm{a}_{42} \mathrm{O}_{87} \mathrm{Si}_{14}\end{array}$ & $\begin{array}{l}\mathrm{C}_{77} \mathrm{H}_{99} \mathrm{~N}_{7} \mathrm{O}_{32} \mathrm{~N} \\
\mathrm{a}_{8} \mathrm{Si}_{2} \cdot 2\left(\mathrm{C}_{3} \mathrm{H}_{7} \mathrm{~N}\right. \\
\mathrm{O}) \cdot 2\left(\mathrm{H}_{2} \mathrm{O}\right)\end{array}$ \\
\hline $\mathrm{T} / \mathrm{K}$ & $173(2)$ & $173(2)$ & $100(2)$ & $173(2)$ & $173(2)$ & $100(2)$ & $120(2)$ \\
\hline$M / \mathrm{g} \mathrm{mol}^{-1}$ & 300.38 & 971.43 & 527.08 & 526.58 & 702.96 & 6667.70 & 2056.95 \\
\hline Crystal system & monoclinic & tetragonal & tetragonal & trigonal & trigonal & trigonal & triclinic \\
\hline $\begin{array}{l}\text { Space group } \\
\text { (No.) }\end{array}$ & $P 2_{1} / n(14)$ & $I 4_{1} / a(88)$ & $I 4_{1} / a(88)$ & $P 3121$ (152) & $R-3 c(167)$ & $R 3$ (146) & $P-1(2)$ \\
\hline$a / \AA$ & $12.2784(4)$ & $41.5542(4)$ & $41.7666(5)$ & $17.1245(2)$ & $30.1227(9)$ & $34.1092(4)$ & $13.3695(9)$ \\
\hline$b / \AA$ & $5.7519(2)$ & $41.5542(4)$ & $41.7666(5)$ & $17.1245(2)$ & $30.1227(9)$ & $34.1092(4)$ & $14.6203(12)$ \\
\hline$c / \AA$ & $21.0637(9)$ & $12.8674(2)$ & $6.4609(1)$ & $16.3889(2)$ & $39.0266(9)$ & $32.7685(4)$ & $15.5828(9)$ \\
\hline$\alpha /^{\circ}$ & 90 & 90 & 90 & 90 & 90 & 90 & $112.092(7)$ \\
\hline$\beta /{ }^{\circ}$ & $95.268(3)$ & 90 & 90 & 90 & 90 & 90 & $95.397(5)$ \\
\hline$\gamma /{ }^{\circ}$ & 90 & 90 & 90 & 120 & 120 & 120 & $112.031(7)$ \\
\hline$U / \AA^{3}$ & $1481.32(10)$ & $22218.8(5)$ & $11270.7(3)$ & $4162.1(1)$ & $30667.4(19)$ & $33016.4(9)$ & 2516.3(3) \\
\hline $\mathrm{Z}$ & 4 & 16 & 16 & 6 & 36 & 3 & 1 \\
\hline $\begin{array}{l}\mu(\mathrm{Mo}-\mathrm{K} \alpha) \\
/ \mathrm{mm}^{-1}\end{array}$ & 0.171 & 1.078 & 0.155 & 0.130 & 0.185 & 1.306 & 0.148 \\
\hline$F(000)$ & 632 & 8224 & 4448 & 1644 & 13056 & 10254 & 1082 \\
\hline $\begin{array}{l}\text { Total } \\
\text { reflections }\end{array}$ & 4531 & 27580 & 34410 & 43250 & 18755 & 83366 & 24833 \\
\hline $\begin{array}{l}\text { Unique } \\
\text { reflections }\end{array}$ & 2597 & 10698 & 6468 & 8445 & 7117 & 21743 & 11074 \\
\hline$R_{\text {int }}$ & 0.017 & 0.032 & 0.032 & 0.024 & 0.021 & 0.049 & 0.081 \\
\hline $\begin{array}{l}\text { Goodness-of- } \\
\text { fit on } F^{2}\end{array}$ & 1.032 & 1.040 & 1.034 & 0.984 & 1.041 & 1.103 & 0.953 \\
\hline 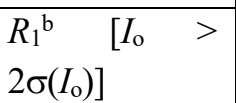 & 0.042 & 0.081 & 0.035 & 0.051 & 0.052 & 0.104 & 0.066 \\
\hline$R_{1}$ (all data) & 0.053 & 0.096 & 0.047 & 0.069 & 0.068 & 0.123 & 0.140 \\
\hline 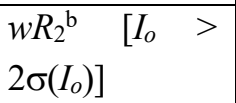 & 0.099 & 0.246 & 0.089 & 0.135 & 0.132 & 0.254 & 0.153 \\
\hline$w R_{2}$ (all data) & 0.107 & 0.260 & 0.095 & 0.141 & 0.142 & 0.286 & 0.189 \\
\hline
\end{tabular}


Table 1: crystallographic data for all structures.

\section{Results and Discussion}

Ditopic linker L1:

The silicon-containing linkers $\mathbf{L} 1-\mathbf{H}_{2}, \mathbf{L} 2-\mathbf{H}_{3}$, and $\mathbf{L} 3-\mathbf{H}_{\mathbf{4}}$ were synthesized via lithiation of the corresponding bromophenylsilanes followed by reaction with $\mathrm{CO}_{2}$ and acidic workup, according to literature procedures. ${ }^{25}$ As part of these studies we were able to obtain X-ray quality crystals of $\mathbf{L 1}-\mathbf{H}_{2}$ via slow evaporation of an acetone solution. This allowed its solidstate structure to be determined, revealing hydrogen bonded polymers (Figure 2).

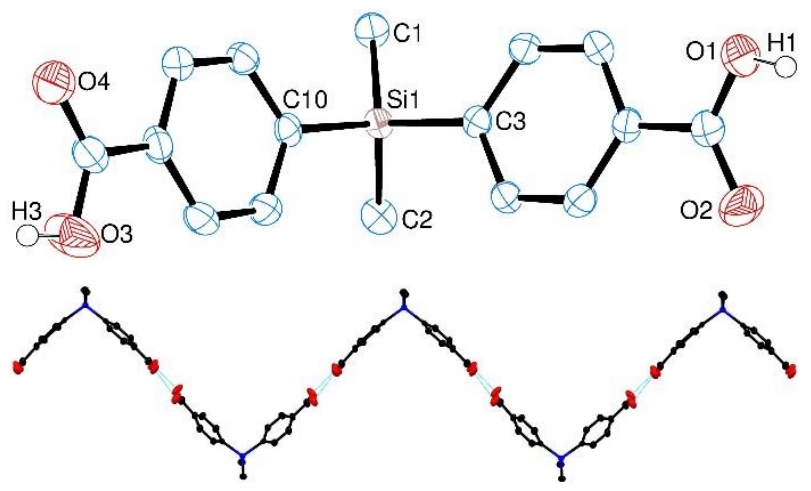

Figure 2: (a) ORTEP diagram of L1-H2. Thermal ellipsoids at $50 \%$ probability and hydrogens (bar carboxylic acid protons) omitted for clarity; (b) extended structure of $\mathbf{L} 1-\mathbf{H}_{2}$ showing a portion of the 1D zig-zag chain generated through hydrogen bonding.

L1-H2 crystallized in the monoclinic space group $P 2_{1} / n$. The molecule is tetrahedral at the central silicon atom, resulting in the two carboxyphenyl units adopting a $\mathrm{V}$-shape in the solid state $\left[\mathrm{C} 3-\mathrm{Si} 1-\mathrm{C} 10=106.49(9)^{\circ}\right]$. Adjacent molecules of $\mathbf{L 1 - \mathbf { H } _ { 2 }}$ assemble via dimeric hydrogen bonding between carboxylic acid groups to form a 1D zig-zag supramolecular polymer (Figure $2 \mathrm{~b}$ ). The H-bonding $\mathrm{O} \cdots \mathrm{O}$ distances are 2.582(2) and 2.711(2) $\AA$, consistent with strong hydrogen bonds ${ }^{51}$ observed in similar hydrogen bonded organic frameworks built from polycarboxylic acids. ${ }^{52,53}$

The proligand $\mathbf{L 1}-\mathbf{H}_{2}$ was then treated with $\mathrm{LiNO}_{3}$ and $\mathrm{LiOH}$ (1:1:1 molar ratio) under solvothermal conditions in $\mathrm{DMF}$ and $\mathrm{MeOH}$ (2:1 ratio). A colorless crystalline solid was formed, which was shown by X-ray diffraction to be $\left[\mathrm{Li}_{4}(\mathbf{L 1})_{2}\left(\mathrm{H}_{2} \mathrm{O}\right)(\mathrm{DMF})_{2}\right](\mathbf{I M P}-\mathbf{2 2}$, where IMP is short for Imperial College London). IMP-22 crystallized in the tetragonal space group $I 4_{1} / a$ with an asymmetric unit consisting of two crystallographically independent ligands, four $\mathrm{Li}^{+}$cations, two coordinated DMF molecules, and one coordinated water. Analysis of the bulk product by PXRD gave a diffraction pattern consistent with the simulated pattern from the single crystal X-ray data (Figure S14, ESI).

The $\mathrm{Li}^{+}$cations in IMP-22 are arranged into an unusual linear motif which runs parallel to the $c$ axis, forming 1D rod SBUs. ${ }^{54}$ These SBUs are constituted of two distinct subunits: the first is a tricyclic ring system consisting of a central 8 -membered $\mathrm{Li}_{2} \mathrm{O}_{4} \mathrm{C}_{2}$ ring (two $\mathrm{Li}^{+}$ cations and two $\left(\mu_{1,3}\right)$-carboxylates) flanked by two four-membered $\mathrm{Li}_{2} \mathrm{O}_{2}$ rings (Figure $3 \mathrm{a}$ ). The second subunit is an unusual $\mathrm{Li}_{6} \mathrm{O}_{16} \mathrm{C}_{6}$ cluster generated from six $\mathrm{Li}^{+}$cations, six 
bridging carboxylate groups, and capped by DMF and water solvent molecules (Figure $3 \mathrm{~b}$ ). One of the two independent $\mathbf{L 1}$ linkers generates the 8-membered ring and also contributes to stabilizing the cluster, whereas the other L1 linker is solely bonded to clusters. Polymeric annulated ring systems with alternating 8- and 4-membered rings have previously been observed in $\mathrm{Li}^{+} \mathrm{MOFs},{ }^{10,15,19}$ and $\mathrm{Bu}$ and Feng recently observed alternating 6- and 4membered rings. ${ }^{55}$ However, IMP-22 is the first structure containing tricyclic repeat units connected by a polyhedral cluster of $\mathrm{Li}^{+}$cations (Figure $3 \mathrm{c}$ ).

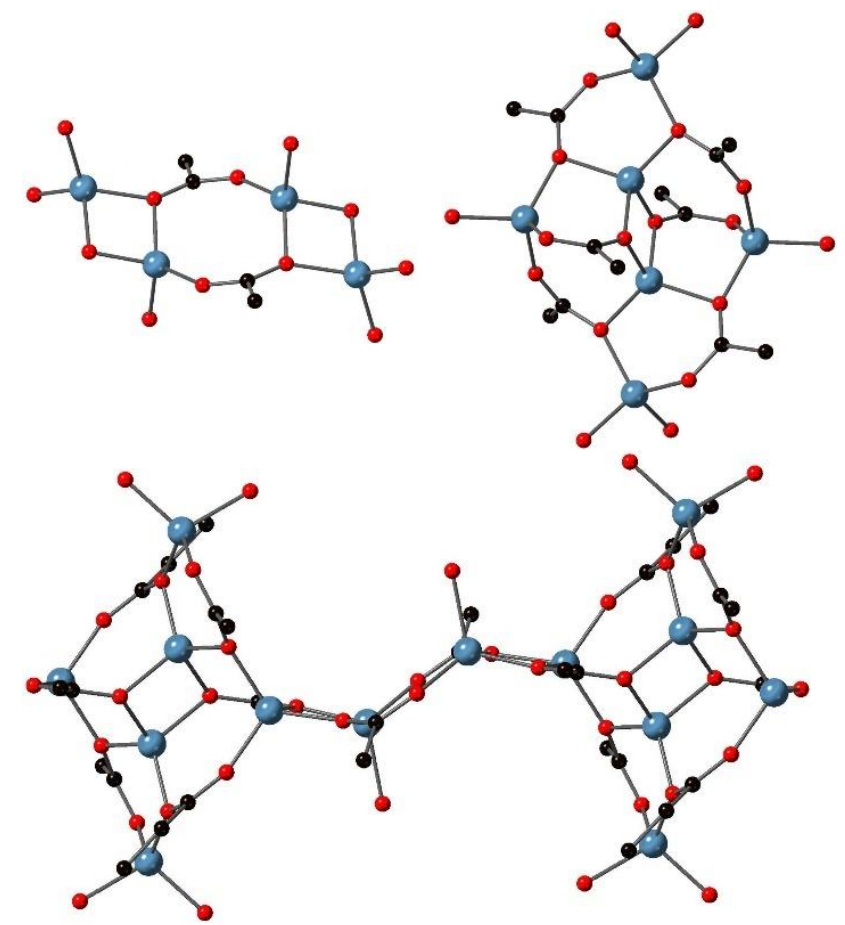

(d)

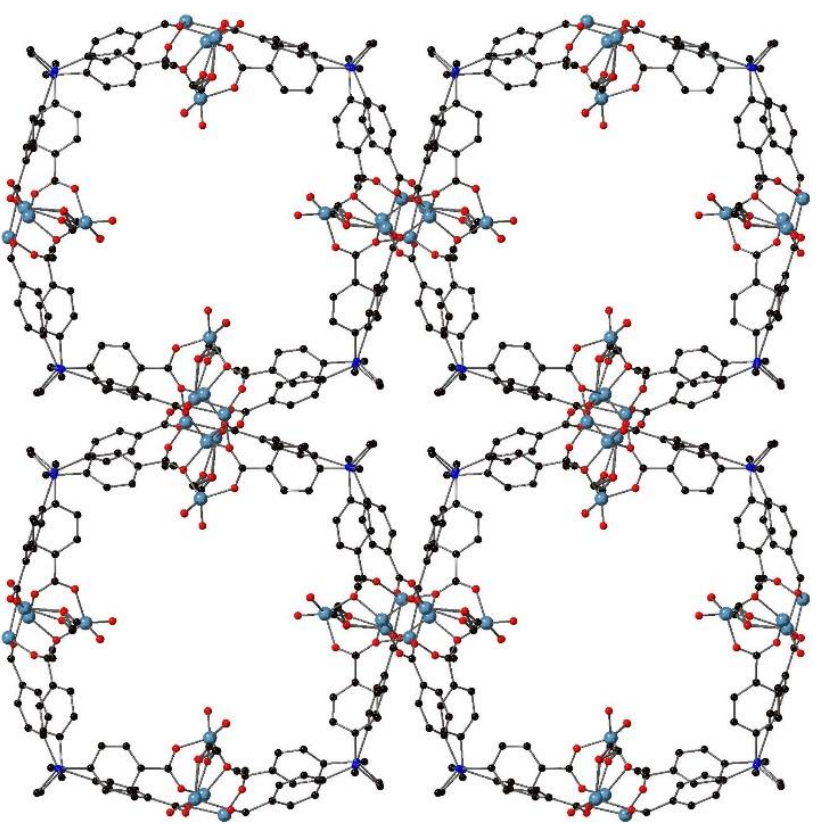

Figure 3: Views of the structure of IMP-22 showing (a) the tricyclic (4-8-4) repeat unit of the SBU; (b) the cluster repeat unit within the SBU; (c) a longer section of the SBU showing two clusters and one tricyclic unit; (d) a view of the MOF from the [001] direction showing the channels (all solvent molecules, bar the coordinating oxygen atoms, are omitted for clarity). Element colors: $\mathrm{C}=$ black; $\mathrm{O}=$ red; $\mathrm{Li}=$ blue. 
Each $\mathrm{Li}^{+}$center in IMP-22 is 4-coordinate although some deviation from ideal tetrahedral geometry is observed; this can be quantified using the $\tau^{\prime}{ }_{4}$ parameter where $\tau^{\prime}{ }_{4}=1$ is ideal tetrahedral and $\tau^{\prime}{ }_{4}=0$ is ideal square planar. ${ }^{56}$ The $\tau^{\prime}{ }_{4}$ values for the $\mathrm{Li}^{+}$cations in IMP-22 range from 0.94 (minimal distortion) to 0.77 (significant distortion); the most distorted $\mathrm{Li}^{+}$ cation is the one which is a component of the 8-membered ring, along with its symmetrygenerated equivalent. There is little difference in bond lengths between the anionic $\mathrm{Li}-\mathrm{O}$ carboxylate bonds and dative covalent $\mathrm{Li}-\mathrm{O}$ bonds to solvent molecules. These are mostly in the expected range 1.906(5) - 1.981(4) $\AA$, although there is one short exception at 1.841(6) $\AA$ which corresponds to the $\mathrm{Li}-\mathrm{O}$ carboxylate bond in the 8-membered ring (plus symmetrygenerated equivalents) and one long exception at 2.058(14) $\AA$ to one of the coordinated DMF molecules.

In order to compare the structural roles of $\mathrm{Li}^{+}$and $\mathrm{Na}^{+}$in MOF construction, the reaction of L1- $\mathbf{H}_{2}$ with $\mathrm{Na}^{+}$was also attempted. Thus, the solvothermal reaction of $\mathbf{L 1}-\mathbf{H}_{2}$ with $\mathrm{NaNO}_{3}$ in a 1:2 ratio gave a colorless crystalline solid which was shown by X-ray crystallographic analysis to be $\left[\mathrm{Na}_{2}(\mathbf{L 1})(\mathrm{DMF})_{2}\right]$ (IMP-23) with two $\mathrm{Na}^{+}$cations, one ligand and two coordinated DMF molecules in the asymmetric unit. Both MOFs crystallized in the same tetragonal space group $I 4_{1} / a$ and contain $1 D$ rod-like SBUs. However, there are some key differences in the composition of these SBUs as discussed below. In addition, the unit cell volumes differ by a factor of two, reflecting the fact that IMP-22 contains twice as many unique ligand environments compared to IMP-23. Analysis of the bulk product of IMP-23 by PXRD gave a diffraction pattern consistent with the simulated pattern from the single crystal X-ray data (Figure S15, ESI).

Each $\mathrm{Na}^{+}$cation in IMP-23 is bound to four carboxylates (one in a bidentate mode and three in a monodentate mode) with one DMF molecule completing the coordination sphere, thus each $\mathrm{Na}^{+}$cation is 6-coordinate (Figure 4a). Although there are two crystallographically distinct cations in the asymmetric unit, the environment around each one is virtually identical, and the steric limitations imposed by the $\kappa^{2}$-carboxylate group means that the geometry is best described as distorted trigonal prismatic rather than octahedral. Each carboxylate anion is in an overall $\mu_{4}$-bridging mode, constituting $\mu_{2}$-bridging through one of the oxygen atoms and $\mu_{3}$-bridging through the other (Figure $4 \mathrm{~b}$ ). This results in a series of edge-sharing $\mathrm{Na}_{2} \mathrm{O}_{2}$ rings which are further bridged by carboxylate anions to form a linear 1D rod SBU (Figure 4c). ${ }^{54}$ These differ from the $\mathrm{Li}^{+}$chains in IMP-22 which were formed of two distinct subunits featuring four different $\mathrm{Li}^{+}$environments, whereas the $\mathrm{Na}^{+}$chains essentially contain one $\mathrm{Na}^{+}$ environment in a highly regular arrangement. This is likely a result of the increased cation size of $\mathrm{Na}^{+}$compared to $\mathrm{Li}^{+}$: the bigger $\mathrm{Na}^{+}$can comfortably adopt higher coordination numbers which leads to the formation of a more regular SBU geometry. To the best of our knowledge, this 1D SBU of $\mathrm{Na}^{+}$cations in IMP-23 is unique.

$(\mathrm{a}, \mathrm{b})$

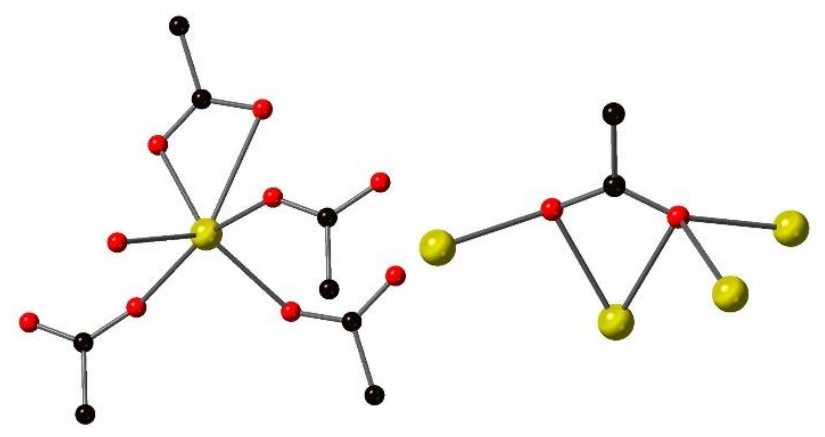


(c)

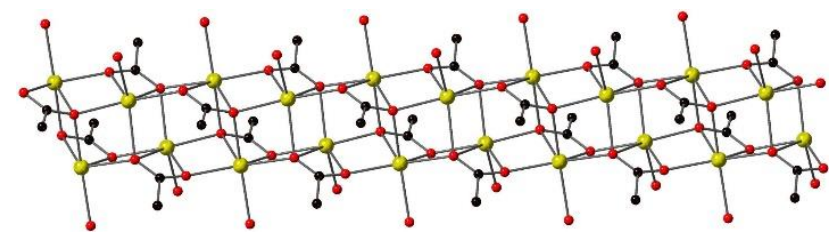

(d)

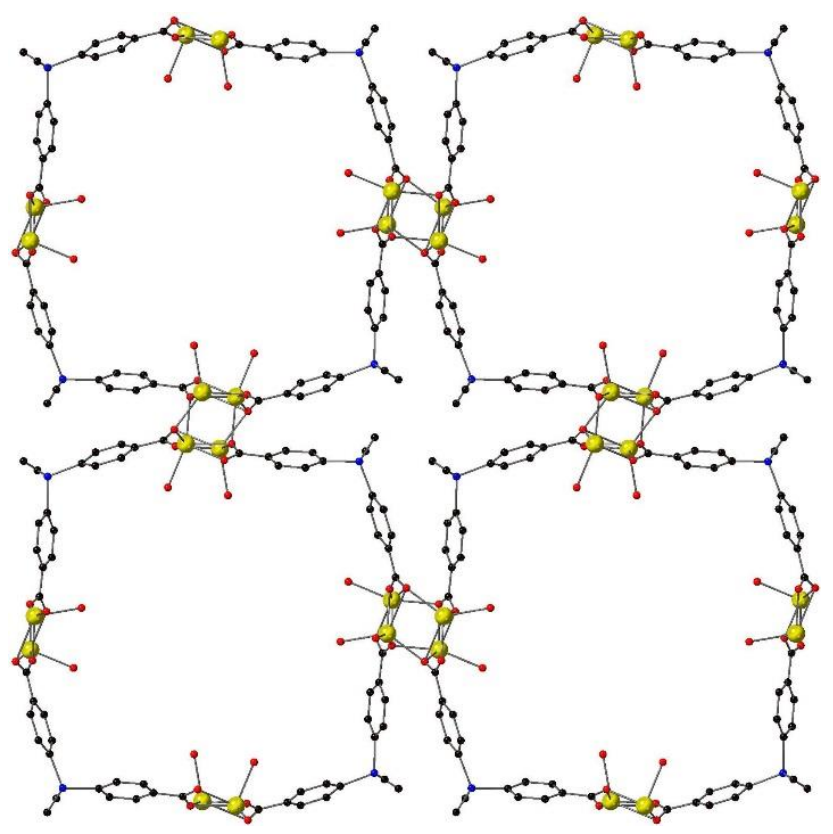

Figure 4: Views of the structure of IMP-23 showing (a) the coordination environment around each $\mathrm{Na}^{+}$cation; (b) the coordination at each carboxylate group; (c) a section of the 1D metal SBU running parallel to the $c$ axis; (d) a view of the MOF with the channels in the [001] direction (all solvent molecules, bar the coordinating oxygen atoms, are omitted for clarity). Element colors: $\mathrm{C}=$ black; $\mathrm{O}=$ red; $\mathrm{Na}=$ yellow.

In IMP-23 the chains of metal cations are crosslinked by $\mathbf{L 1}$, resulting in a $3 \mathrm{D}$ polymeric structure with channels running along the [001] direction. Even though the 1D SBUs for IMP-22 and IMP-23 are different, the topological connectivity of L1 in each of the two MOFs is almost identical. Each ligand bridges two rod SBUs, and each channel is formed by four SBUs connected by four ligands (Figures 3d, 4d). Both MOFs contain solvent-filled square channels of $\sim 14 \times 14 \AA$ (IMP-22, Figure 3d) or $\sim 15 \times 15 \AA$ (IMP-23, Figure 4d; the distances take into account van der Waals radii of atoms on the edge of the channels). With theoretical removal of all solvents, the solvent accessible volumes (SAV) as calculated by PLATON are 47\% (IMP-22) and 46\% (IMP-23).

For both IMP-22 and IMP-23, the scXRD data indicated that non-coordinating DMF molecules were present in the pores. These could not be modelled successfully hence they were removed using the SQUEEZE routine within PLATON (see ESI for details). ${ }^{48}$ TGA of IMP-22 (Figure S18) and IMP-23 (Figure S19) under $\mathrm{N}_{2}$ each exhibited a mass loss consistent with a theoretical mass loss of all DMF (coordinated and non-coordinated) in the temperature range $50{ }^{\circ} \mathrm{C}$ to $230{ }^{\circ} \mathrm{C}\left(180{ }^{\circ} \mathrm{C}\right.$ for IMP-23). However, during preparation for gas sorption studies, a sample of IMP-22 was heated in vacuo at $50{ }^{\circ} \mathrm{C}$ for 16 hours which resulted in some loss of crystallinity of the sample: the PXRD peaks became broader and less well defined (Figure S14). Subsequent attempts to calculate the surface area of IMP-22 and 
IMP-23 by BET analysis indicated that little or no porosity was present, likely due to structural collapse induced by solvent loss.

Tritopic linker L2:

Treatment of $\mathrm{LiNO}_{3}$ with the tripodal proligand $\mathbf{L} 2-\mathbf{H}_{3}$ in DMF (3:1 molar ratio) led to the formation of colorless crystals which were analyzed by scXRD. This revealed that [ $\left.\mathrm{Li}_{3}(\mathbf{L 2})(\mathrm{DMF})\right]$ (IMP-24) crystallized in the chiral space group $P 3_{1} 21$ with one ligand, four $\mathrm{Li}$ cation sites and one coordinated DMF comprising the asymmetric unit. One of the Li cations lies on a 2-fold axis and another is disordered over a 2-fold axis resulting overall in a 1:3 ratio of $\mathbf{L} \mathbf{2}$ to $\mathrm{Li}$ in the structure. The chirality arises from the formation of right-handed helical Li-based chains which are interconnected by $\mathbf{L 2}$ to form a 3D structure (Figure 5). The pitch of the helix (16.4 $\AA$ ) is determined by the ligand: two of the three arms of the ligand intraconnect the helix, holding it together, whilst the third arm of the ligand bridges to a neighboring helix. The generation of an enantiomerically pure chiral MOF from achiral starting materials is particularly rare and as far as we are aware only two prior examples have been reported for $\mathrm{Li}^{+}$MOFS. ${ }^{55,57}$

(a)
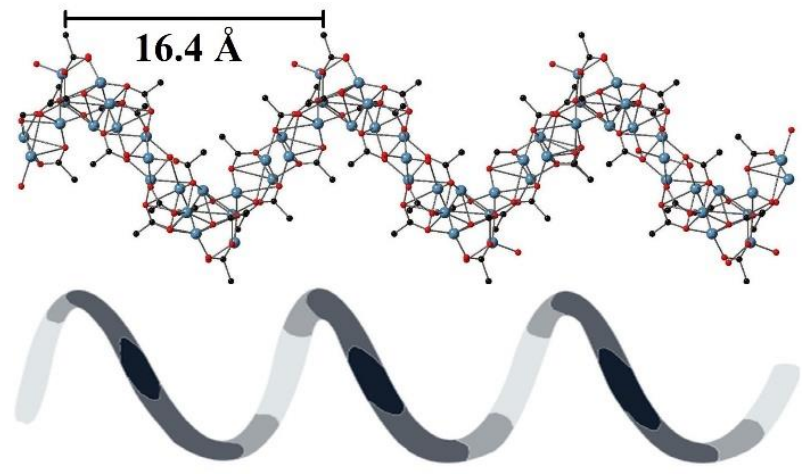

(b)

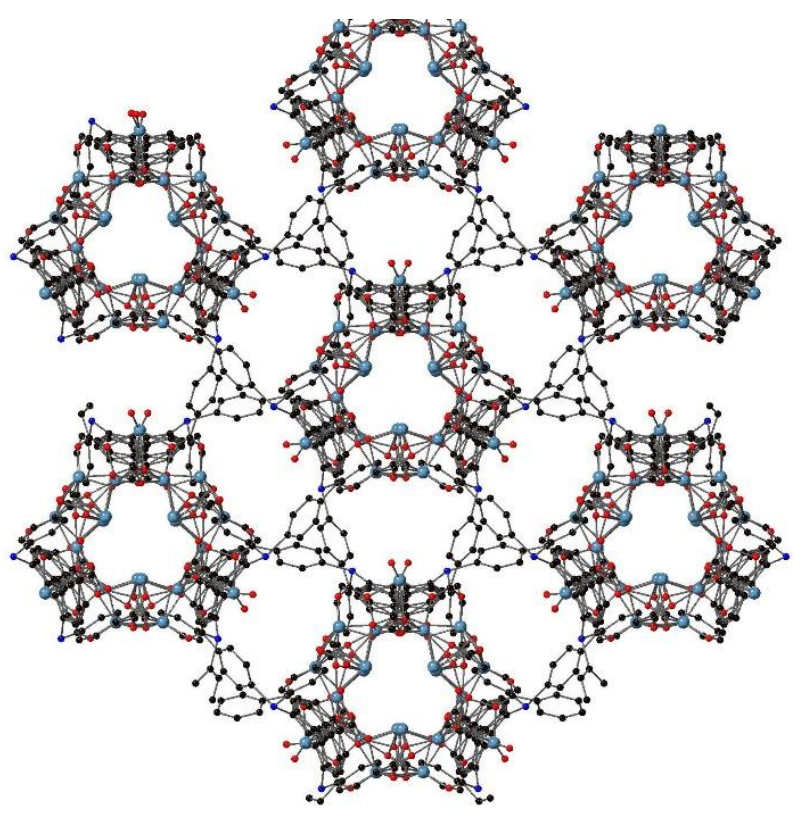


Figure 5: Views of the structure of IMP-24 showing (a) the pitch of the helical metal node; (b) the interconnection of the helices by L3, looking down the [001] direction. Solvents (bar coordinating oxygens) omitted for clarity. Element colors: $\mathrm{C}=$ black; $\mathrm{O}=$ red; $\mathrm{Li}=$ blue.

Owing to the presence of significant amounts of positional disorder within the ligand arms and the coordinated DMF molecule, it is challenging to accurately describe the coordination environment at each $\mathrm{Li}^{+}$center. Further details regarding the crystallography can be found in the ESI.

IMP-24 readily underwent decomposition when the crystals were removed from the solvent. This meant it was not possible to ascertain the bulk purity of the MOF using PXRD. Nevertheless, several single crystals from different batches of IMP-24 were analyzed by single crystal X-ray diffraction and gave identical unit cell parameters in each case. Owing to this decomposition no further studies or sorption measurements were carried out on IMP-24.

In contrast, treatment of $\mathbf{L} 2-\mathbf{H}_{3}$ with $\mathrm{NaNO}_{3}$ in DMF in a 3:1 molar ratio led to the formation of two morphologies of colorless crystals: rhombohedra and rods. Crystallographic analysis of the former revealed that $\left[\mathrm{Na}_{12}(\mathbf{L 3})_{4}(\mathrm{DMF})_{4}\right](\mathbf{I M P}-\mathbf{2 5})$ had formed. The asymmetric unit contains $4 / 3$ equivalents of $\mathbf{L 2}$, four $\mathrm{Na}^{+}$cations and $4 / 3$ DMF molecules. Each $\mathrm{Na}^{+}$cation is in a markedly different coordination environment (Figures 6a-d). These assemble to form a MOF with a single 3D metal-based node which is, to the best of our knowledge, unique: no other 3D nodes or SBUs appear in the MOF literature.

The 3D nature of the sodium-based node, or SBU, is clearly visible when viewed from different directions. The node itself is formed of $\mathrm{Na}^{+}$cations with bridging carboxylate groups, leading to an SBU which is continuous in all three directions and can be generated solely from sodium and oxygen atoms (Figures 6e, f). The organic portion of $\mathbf{L} \mathbf{2}$ is located within the spaces of the SBU, hence the MOF is densely packed. There are, however, small triangular channels in the [001] direction which are filled with coordinated DMF solvent molecules (Figure S7, ESI).

$(a, b, c, d)$

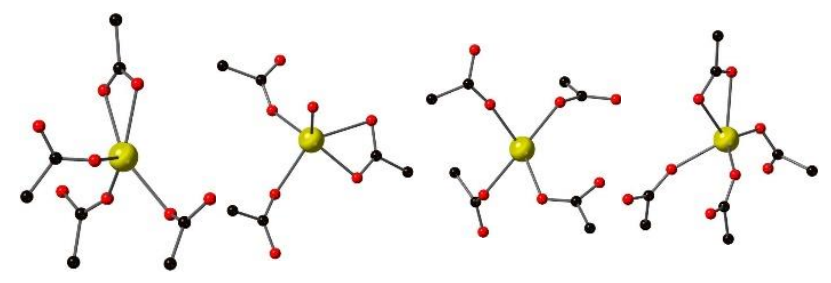

(e)

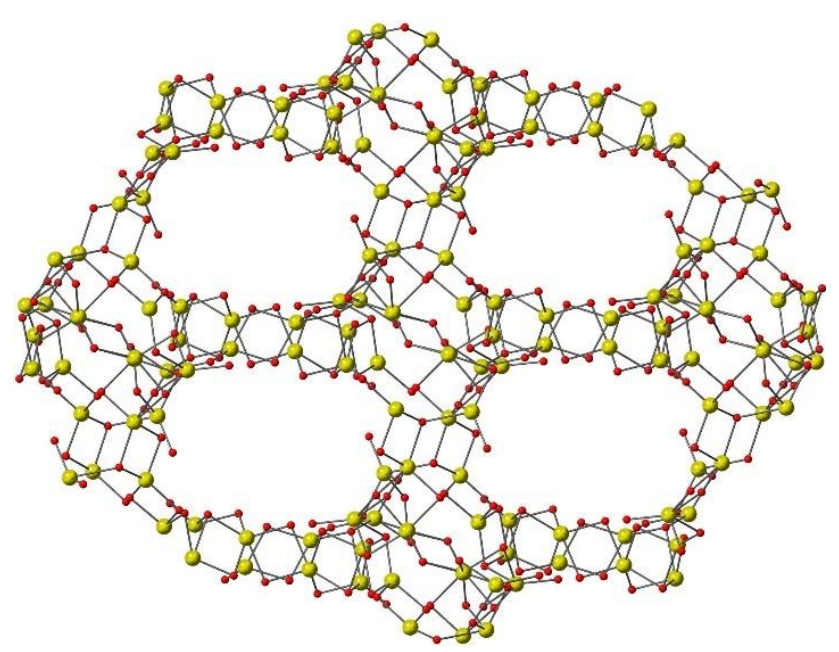




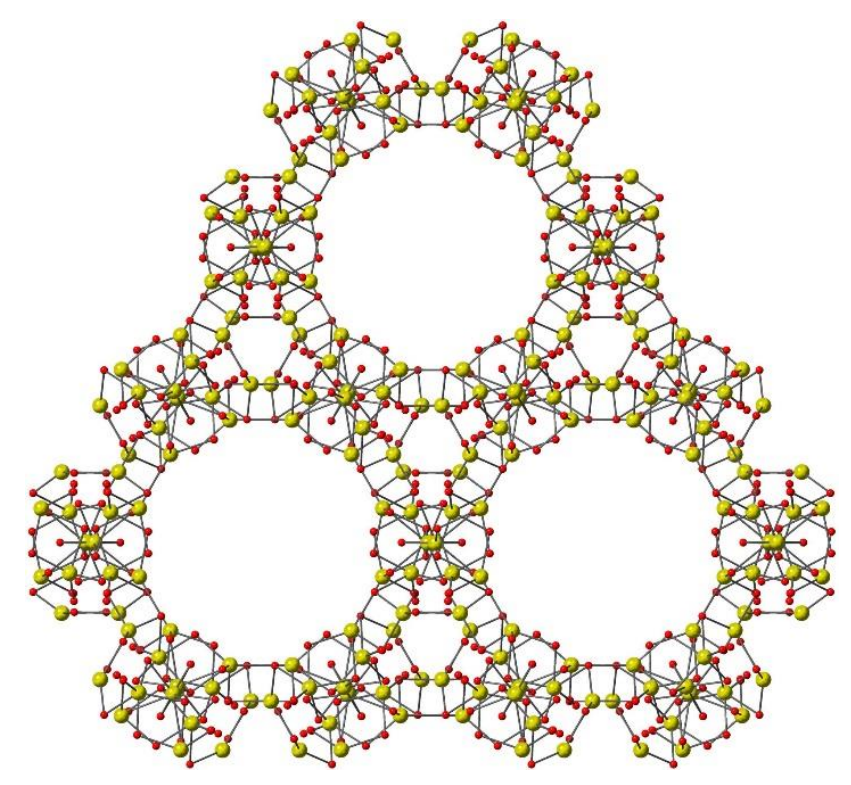

Figure 6: views of the structure of IMP-25 showing the coordination environment around (a) $\mathrm{Na} 1$; (b) Na2; (c) Na3; (d) Na4; (e) the 3D metal node (Na and $\mathrm{O}$ only) displaying the ordering in the [010] direction (note the [100] direction looks identical); (f) the ordering in the [001] direction. Element colors: $\mathrm{C}=$ black; $\mathrm{O}=$ red; $\mathrm{Na}=$ yellow.

Assigning coordination numbers and geometries to $\mathrm{Na}^{+}$cations can be complicated because the larger size of $\mathrm{Na}^{+}$typically results in the adoption of higher coordination numbers (ionic radius of 6-coordinate $\mathrm{Na}^{+}=1.02 \AA$ vs. $0.59 \AA$ for 4 -coordinate $\left.\mathrm{Li}^{+}\right) .{ }^{58}$ For IMP-25, an upper limit for an $\mathrm{Na}-\mathrm{O}$ bond was set at $3.5 \AA$, which is $0.5 \AA$ below the sum of the van der Waals radii for the two elements ( $\mathrm{vdW}$ radii of $\mathrm{Na}+\mathrm{O}=4.00 \AA$ ). ${ }^{59,}{ }^{60}$ Hence the Na1 (Figure 6a), $\mathrm{Na} 2$ (Figure 6b), and Na4 (Figure 6d) cations are all in 5-coordinate environments with $\tau_{5}$ parameters of $0.16,0.06$ and 0.02 respectively. ${ }^{61}$ This indicates the geometry at each $\mathrm{Na}^{+}$ cation is very mildly distorted away from ideal square based pyramidal. In contrast, Na3 (Figure $6 \mathrm{c}$ ) is in a 4-coordinate environment where the $\tau^{\prime}{ }_{4}$ parameter of 0.63 indicates severe distortion away from ideal tetrahedral. ${ }^{56}$ A fuller analysis of the $\mathrm{Na}-\mathrm{O}$ bond lengths, and the geometries of the $\mathrm{Na}^{+}$cations, can be found in the ESI.

Crystallographic analysis of the rod-shaped crystals formed from the reaction of $\mathrm{NaNO}_{3}$ and L2-H3 revealed that a structure with a slightly different composition had formed:

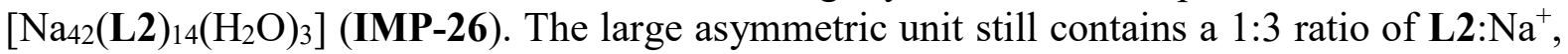
but the major difference between IMP-25 and IMP-26 is the presence of water in the latter. When viewed down the $\mathrm{c}$ axis the gross structures of the nodes of IMP-25 and IMP-26 appear similar, with clear hexagonal channels which are filled by the organic component of L2. The smaller channels in IMP-26 contain both coordinated and non-coordinated solvents (water and DMF respectively) although the DMF was removed using SQUEEZE (see ESI for further details).

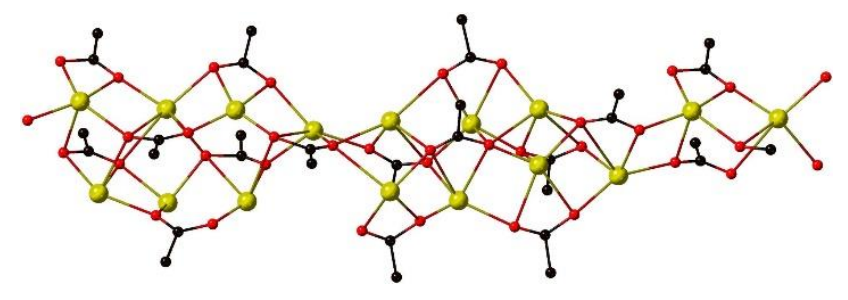


(b)

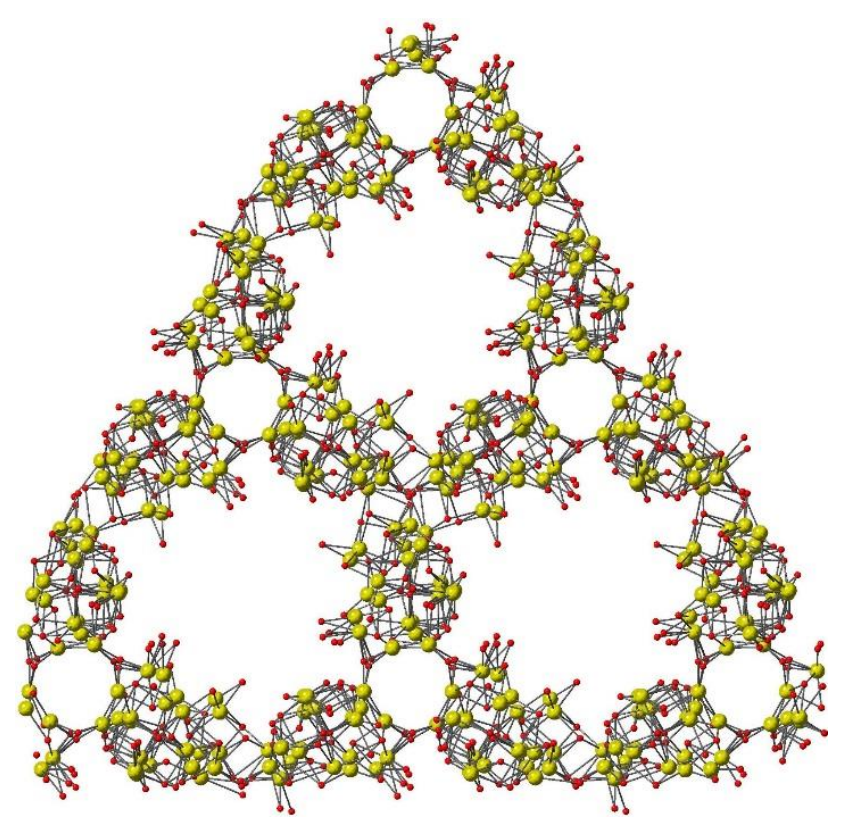

(c)

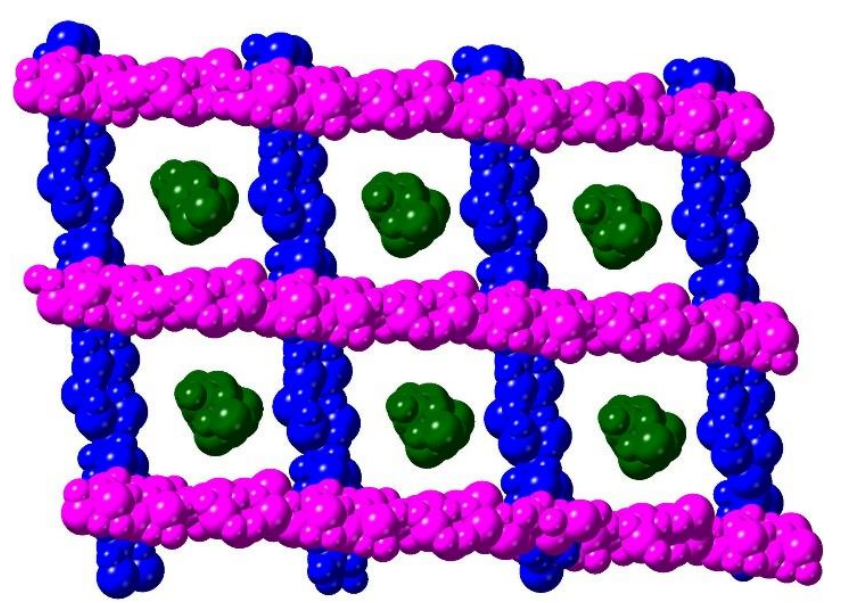

Figure 7: (a) view of a portion of the 1D rod SBU; (b) view of the structure of IMP-26 in the [001] direction showing just the 1D rod SBUs; (c) false-colored view of IMP-26 in the [1 $\overline{1}$ $\overline{1}$ ] direction showing the three orientations of the rod SBUs. Element colors: $\mathrm{C}=$ black; $\mathrm{O}$ $=$ red; $\mathrm{Na}=$ yellow.

Closer inspection of the nodes in IMP-26 reveals that the gross structure is different to that of IMP-25: the MOF is formed of intersecting linear 1D rod SBUs containing $\mathrm{Na}^{+}$cations bridged by carboxylates and water molecules (Figure 7a). When the structure is viewed down the $\mathrm{c}$ axis, the SBUs overlap and thus appear similar to IMP-25 (Figure 7b), but they are actually separate entities which are not directly bonded to each other and run in three different directions (Figure 7c). There is a large amount of positional disorder within the ligands and the metal nodes which make a full analysis of the SBU composition challenging (see the ESI for a fuller description of the crystallography for IMP-26). 
When all solvents are theoretically removed from IMP-26, three triangular channels which run parallel to the $\mathrm{c}$ axis (base and height both $\sim 10 \AA$ ) are generated. Although each individual channel is relatively small, the combined volume is consistent with a calculated SAV of 37\%. In contrast, IMP-25 has a calculated SAV of just $16 \%$ when all coordinated solvent molecules are theoretically removed.

Although the formation of two separate crystal morphologies was reproducible and individual crystals could be isolated by crystal picking, large scale chemical separation of IMP-25 and IMP-26 proved impossible. Despite numerous attempts we were also unable to selectively form just one of the two MOFs by altering the reaction conditions. Bulk characterization of the sample was consequently carried out on a mixture of IMP-25 and IMP-26 (Figure S16), with peaks corresponding to both MOFs seen in the as-synthesized sample. Since we were unable to obtain either MOF in pure form, no further studies or gas sorption measurements were carried out.

Taken together, the three structures IMP-24, IMP-25, and IMP-26 have demonstrated the ability of the tridentate $\mathbf{L 2}$ linker to form novel and rare structural motifs. All three MOFs crystallize in trigonal space groups but the cell parameters are notably different, leading to significant contrasts between the three structures. The $\mathrm{Li}^{+}$-based MOF IMP-24 is a rare example of a MOF containing a chiral, helical Li-based SBU whereas the $\mathrm{Na}^{+}$-based MOFs show no inclination to form similar helices. The two $\mathrm{Na}^{+}$-based MOFs appear similar, especially when viewed in the [001] direction, but are in fact quite different with IMP-25 containing a unique 3D metal-based node, whereas IMP-26 is formed of intersecting 1D rod SBUs which run in three different directions.

Tetratopic linker L3:

The reaction of $\mathrm{LiNO}_{3}$ with the tetrahedral proligand $\mathbf{L 3}-\mathbf{H}_{4}$ in DMF (4:1 molar ratio) under solvothermal conditions led to the growth of colorless crystals in good yield. Although the single crystal X-ray dataset was only of sufficient quality to show the atomic connectivity, the network of $\left[\mathrm{Li}_{4}(\mathbf{L 3})\left(\mathrm{H}_{2} \mathrm{O}\right)_{2}(\mathrm{DMF})\right](\mathbf{I M P}-27 \mathbf{L i})$ could be unambiguously assigned. It crystallized in the triclinic space group $P-1$ with one fully deprotonated $\mathbf{L 3}$, four lithium cations, one coordinated DMF molecule and two molecules of water. A very similar framework was reported by Moon and co-workers who also reacted $\mathrm{LiNO}_{3}$ and $\mathbf{L 3}-\mathbf{H}_{4}$ to form a MOF using $N, N$-diethylformamide and ethanol as solvents. ${ }^{38}$ The two frameworks are topologically equivalent and the cell parameters are very similar (but not identical), which is likely a result of the different sizes of the solvents attached to the $\mathrm{Li}^{+}$cations. Analysis of the bulk crystals of IMP-27Li by PXRD produced diffraction patterns consistent with simulated patterns generated from scXRD data (Figure S17).

An analogous reaction between $\mathrm{NaNO}_{3}$ and $\mathbf{L 3}-\mathrm{H}_{4}$ in DMF (4:1 molar ratio) resulted in the growth of a small amount of colorless crystalline material which was suitable for scXRD analysis. The compound $\left[\mathrm{Na}_{4}(\mathbf{L 3})(\mathrm{DMF})_{4}\left(\mathrm{H}_{2} \mathrm{O}\right)_{4}\right]$ (IMP-27Na) crystallized in the same space group as IMP-27Li $(P-1)$ but with significantly different cell parameters. The asymmetric unit of IMP-27Na contained one fully deprotonated $\mathbf{L 3}$, four $\mathrm{Na}^{+}$cations, eight coordinated solvent molecules (four DMF and four water), and two uncoordinated solvent molecules (one $\mathrm{DMF}$ and one water). Despite the presence of bigger cations and increased coordination numbers, the overall structural topology is not disrupted: both IMP-27Li and IMP-27Na contain similar 1D chains (rod SBUs) of metal cations bridged by carboxylate groups and water. 
Two of the $\mathrm{Na}^{+}$cations have six $\mathrm{Na}-\mathrm{O}$ bonds which are all within the range $2.280(16)-$ 2.584(4) $\AA$ (allowing for the disordered DMF). Both these $\mathrm{Na}^{+}$cations can thus be described as a slightly distorted octahedron with no significant long-range interactions. The other two $\mathrm{Na}^{+}$cations are located in 7-coordinate environments with six $\mathrm{Na}-\mathrm{O}$ bonds in the range $2.285(4)-2.799(4) \AA$ and a longer $\mathrm{Na}-\mathrm{O}$ interaction which is still below $3.5 \AA .{ }^{60}$ These adopt different geometries, notably a distorted square-capped trigonal prism and a slightly distorted pentagonal bipyramid (see Figures S11a-d in the ESI).

The 1D rod SBUs in IMP-27Na are made up of well-defined repeating units consisting of two asymmetric units. Thus, eight $\mathrm{Na}^{+}$cations are bridged by six carboxylates and eight water molecules, with eight terminal DMF molecules and two further carboxylate groups, which bridge across neighboring repeat units (Figure 8a).

(a)
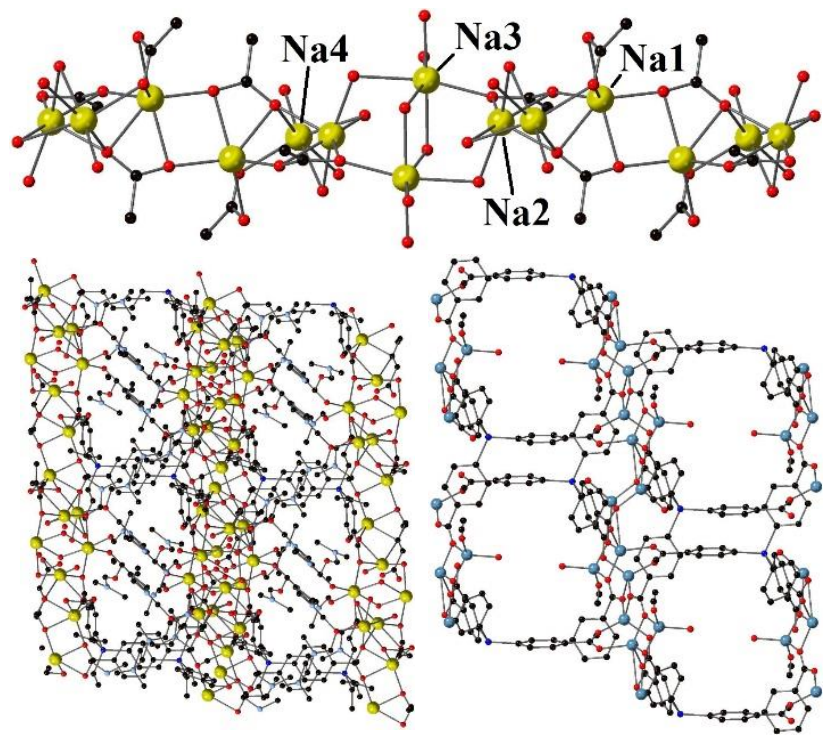

Figure 8: (a) view of the repeat unit in the metal node of IMP-27Na; (b) view of the solventfilled channels in IMP-27Na viewed down the [110] direction (c) view of the corresponding channels in IMP-27Li viewed down the [001] direction. Element colors: $\mathrm{C}=$ black; $\mathrm{O}=$ red; $\mathrm{Li}=$ blue; $\mathrm{Na}=$ yellow.

The extra solvent molecules coordinating to the metal node in IMP-27Na results in a significantly reduced potential void space $(0 \%$ SAV) when compared to IMP-27Li $(32 \%$ SAV) assuming complete removal of non-coordinating solvents in both cases. This can be seen more clearly in Figures $8 \mathrm{~b}$ and $8 \mathrm{c}$. Theoretical removal of all coordinated solvent increases the SAVs to 39\% (IMP-27Na) and 45\% (IMP-27Li). Heating a ground sample of IMP-27Li in vacuo at $50{ }^{\circ} \mathrm{C}$ for 16 hours led to a broadening of the PXRD peaks due to structural collapse (Figure S17). In addition, gas sorption analysis carried out on IMP-27Li (Figure S22) indicated the material to be essentially non-porous, which is also in keeping with structural collapse of the MOF on evacuation. We were unable to obtain any gas sorption measurements for IMP-27Na owing to the very low synthetic yields obtained for this MOF. 


\section{Conclusions}

Prior to this work, few MOFs with the light, oxophilic metals $\mathrm{Li}^{+}$and $\mathrm{Na}^{+}$were known in the literature. As well as increasing the number of known examples of these 'light metal' MOFs this work has revealed several novel SBU structural motifs, most notably a 3D SBU in IMP25.

The $\mathrm{Li}^{+}$and $\mathrm{Na}^{+}$MOFs (IMP-22 and IMP-23 respectively) generated from $\mathbf{L} 1$ (two 'armed' bent connector) are almost isostructural with both structures containing rod SBUs running parallel to the $c$ axis. These differ only in the arrangement of the metal cations and carboxylate groups within them, where IMP-22 contains a tricyclic 4-8-4 ring system alternating with polyhedral $\mathrm{Li}_{6} \mathrm{O}_{16} \mathrm{C}_{6}$ clusters, whereas IMP-23 contains a more regular arrangement of cations and bridging carboxylates.

The $\mathrm{Li}^{+}$MOF IMP-24 generated from L2 (three 'armed' tripodal connector) is a chiral structure containing individual helical metal-based nodes (generated from achiral starting materials) with a pitch of $16.4 \AA$. The helical motif is rare in MOF chemistry and has only been reported twice before in $\mathrm{Li}^{+}$-based MOFs. Switching the metal to $\mathrm{Na}^{+}$leads to the formation of a mixture of two MOFs from the same reaction: one is built from a unique 3D metal-based node (IMP-25) whereas the other is constructed from $\mathrm{Na}^{+}$-based rods which run in three distinct directions (IMP-26).

Comparison of the $\mathrm{Li}^{+}$- and $\mathrm{Na}^{+}$-based MOFs (IMP-27Li and IMP-27Na respectively) formed using L3 (four 'armed' tetrahedral connector) showed both networks to be built from 1D rod SBUs. In the case of IMP-27Li the structure is essentially isostructural to a literature example built from the same components. The $\mathrm{Na}^{+}$analog IMP-27Na is also isotopological although the larger cation size of $\mathrm{Na}^{+}$compared to $\mathrm{Li}^{+}$resulted in increased metal coordination numbers (up to 7-coordinate), resulting in a different SBU substructure which also incorporates bridging solvent molecules.

Together, these structures illustrate the wide range of diverse structural motifs possible for MOFs with s-block metals. Despite the fact that none of the MOFs in this study were stable under evacuation, the rare and unusual metal nodes generated from these linkers with small, oxophilic metal centers shows the potential for further investigations into these 'light metal' materials.

\section{Acknowledgements}

We would like to thank EPSRC for financial support (K.R., L.C.D., E.A.: EP/M507878/1), also Imperial College (D.P.), and the Imperial College President's Ph.D. Scholarship Scheme (L.C.D.). We would also like to thank Prof. Anthony Kucernak for assistance with BET measurements, and Richard Sweeney for access to pXRD.

\section{Electronic Supplementary Information}

Further experimental and crystallographic details are included as electronic supplementary information. Crystallographic data in cif format have been deposited with the Cambridge Crystallographic Data Centre (CCDC) and given numbers CCDC 1573356, 1573357, 1871441-1871445. 


\section{References}

1. Sun, C.-Y.; Qin, C.; Wang, X.-L.; Su, Z.-M. Metal-organic frameworks as potential drug delivery systems. Expert Opin. Drug Deliv., 2013, 10, 89.

2. Liu, J.; Chen, L.; Cui, H.; Zhang, J.; Zhang, L.; Su, C.-Y. Applications of metal-organic frameworks in heterogeneous supramolecular catalysis. Chem. Soc. Rev., 2014, 43, 6011.

3. Bao, Z.; Chang, G.; Xing, H.; Krishna, R.; Ren, Q.; Chen, B. Potential of microporous metal-organic frameworks for separation of hydrocarbon mixtures. Energy Environ. Sci., 2016, 9, 3612.

4. Kang, Z.; Fan, L.; Sun, D. Recent advances and challenges of metal-organic framework membranes for gas separation. J. Mater. Chem. A, 2017, 5, 10073.

5. Murray, L. J.; Dincă, M.; Long, J. R. Hydrogen storage in metal-organic frameworks. Chem. Soc. Rev., 2009, 38, 1294.

6. Sumida, K.; Rogow, D. L.; Mason, J. A.; McDonald, T. M.; Bloch, E. D.; Herm, Z. R.; Bae, T. H.; Long, J. R. Carbon dioxide capture in metal-organic frameworks. Chem. Rev., 2012, 112, 724.

7. Yu, X.; Tang, Z.; Sun, D.; Ouyang, L.; Zhu, M. Recent advances and remaining challenges of nanostructured materials for hydrogen storage applications. Prog. Mater. Sci., 2017, 88, 1.

8. Lin, Y.; Kong, C.; Zhang, Q.; Chen, L. Metal-Organic Frameworks for Carbon Dioxide Capture and Methane Storage. Adv. Energy Mater., 2017, 7, 1601296.

9. Banerjee, D.; Parise, J. B. Recent Advances in s-Block Metal Carboxylate Networks. Cryst. Growth Des., 2011, 11, 4704.

10. Abrahams, B. F.; Grannas, M. J.; Hudson, T. A.; Robson, R. A Simple Lithium(I) Salt with a Microporous Structure and Its Gas Sorption Properties. Angew. Chem. Int. Ed., 2010, 49, 1087.

11. Ong, T. T.; Kavuru, P.; Nguyen, T.; Cantwell, R.; Wojtas, Y.; Zaworotko, M. J. 2:1 Cocrystals of Homochiral and Achiral Amino Acid Zwitterions with $\mathrm{Li}^{+}$Salts: Water-Stable Zeolitic and Diamondoid Metal-Organic Materials. J. Am. Chem. Soc., 2011, 133, 9224.

12. El Osta, R.; Frigoli, M.; Marrot, J.; Medina, M. E.; Walton, R. I.; Millange, F. Synthesis, Structure, and Crystallization Study of a Layered Lithium Thiophene-Dicarboxylate. Cryst. Growth Des., 2012, 12, 1531.

13. Cheng, P.-C.; Tseng, F.-S.; Yeh, C.-T.; Chang, T.-G.; Kao, C.-C.; Lin, C.-H.; Liu, W.-R.; Chen, J.-S.; Zimae, V. Synthesis, structures, and properties of alkali and alkaline earth coordination polymers based on V-shaped ligand. CrystEngComm, 2012, 14, 6812.

14. Clough, A.; Zheng, S.-T.; Zhao, X.; Lin, Q.; Feng, P.; Bu, X. New Lithium Ion Clusters for Construction of Porous MOFs. Cryst. Growth Des., 2014, 14, 897.

15. Abrahams, B. F.; Dharma, D. A.; Grannas, M. J.; Hudson, T. A.; Maynard-Caseley, H. E.; Oliver, G. R.; Robson, R.; White, K. F. Isomeric Ionic Lithium Isonicotinate Three-Dimensional Networks and Single-Crystal-to-Single-Crystal Rearrangements Generating Microporous Materials. Inorg. Chem., 2014, 53, 4956.

16. Tominaka, S.; Yeung, H. H.-M.; Henke, S.; Cheetham, A. K. Coordination environments and $\pi$ conjugation in dense lithium coordination polymers. CrystEngComm, 2016, 18, 398.

17. Wan, W.; Zhu, Z.-B.; Huo, L.-H.; Deng, Z.-P.; Zhao, H.; Gao, S. Syntheses, structures and luminescent properties of lithium(I)-sulfonate complexes constructed from ortho-hydroxyl arenedisulfonic acids: structural evolution tuned by the $\mathrm{pH}$, coordination geometry and modes. CrystEngComm, 2012, 14, 5274. 
18. Kim, T. K.; Lee, J. H.; Moon, D.; Moon, H. R. Luminescent Li-based metal-organic framework tailored for the selective detection of explosive nitroaromatic compounds: direct observation of interaction sites. Inorg. Chem., 2013, 52, 589.

19. Aliev, S. B.; Samsonenko, D. B.; Rakhmanova, M. I.; Dybtsev, D. N.; Fedin, V. P. Syntheses and Structural Characterization of Lithium Carboxylate Frameworks and Guest-Dependent Photoluminescence Study. Cryst. Growth Des., 2014, 14, 4355.

20. Zheng, S.-T.; Li, Y.; Wu, T.; Nieto, R. A.; Feng, P.; Bu, X. Porous Lithium Imidazolate Frameworks Constructed with Charge-Complementary Ligands. Chem. Eur. J., 2010, 16, 13035.

21. Chen, X.; Bu, X.; Lin, Q.; Zhai, Q.-G.; Zhao, X.; Wang, Y.; Feng, P. Organization of Lithium Cubane Clusters into Three-Dimensional Porous Frameworks by Self-Penetration and Self-Polymerization. Cryst. Growth Des., 2016, 16, 6531.

22. Raja, D. S.; Luo, J.-H.; Wu, C.-Y.; Cheng, Y.-J.; Yeh, C.-T.; Chen, Y.-T.; Lo, S.-H.; Lai, Y.-L.; Lin, C.-H. Solvothermal Synthesis, Structural Diversity, and Properties of Alkali Metal-Organic Frameworks Based on V-shaped Ligand. Cryst. Growth. Des., 2013, 13, 3785.

23. Raja, D. S.; Luo, J.-H.; Yeh, C.-T.; Jiang, Y.-C.; Hsu, K.-F.; Lin, C.-H. Novel alkali and alkaline earth metal coordination polymers based on 1,4-naphthalenedicarboxylic acid: synthesis, structural characterization and properties. CrystEngComm, 2014, 16, 1985.

24. Choi, A.; Kim, Y. K.; Kim, T. K.; Kwon, M.-S.; Lee, K. T.; Moon, H. R. 4,4'-Biphenyldicarboxylate sodium coordination compounds as anodes for Na-ion batteries. J. Mater. Chem. A, 2014, 2, 14986.

25. Davies, R. P.; Less, R. J.; Lickiss, P. D.; Robertson, K.; White, A. J. P. Tetravalent Silicon Connectors $\mathrm{Me}_{\mathrm{n}} \mathrm{Si}\left(\mathrm{p}-\mathrm{C}_{6} \mathrm{H}_{4} \mathrm{CO}_{2} \mathrm{H}\right)_{4-\mathrm{n}}(\mathrm{n}=0,1,2)$ for the Construction of Metal-Organic Frameworks. Inorg. Chem., 2008, 47, 9958 .

26. Gupta, V.; Khullar, S.; Kumar, S.; Mandal, S. K. Construction of a robust pillared-layer framework based on the rare paddlewheel subunit $\left[\mathrm{Mn}_{2}{ }_{2}\left(\mu-\mathrm{O}_{2} \mathrm{CR}\right)_{4} \mathrm{~L}_{2}\right]$ : synthesis, crystal structure and magnetic properties. Dalton Trans., 2015, 44, 16778.

27. Yan, Y.; Liu, S.; Guo, M.; Guo, X.; Guo, H. Construction of two mixed-ligand coordination polymers presenting unusual polyrotaxane-like entanglements. Inorg. Chem. Commun., 2016, 71, 98.

28. Cai, Y. Crystal structure of catena-poly- $\left\{\right.$ aqua- $\left[\mu_{2}-1,2-b i s\left(\left(1 \mathrm{H}-\right.\right.\right.$ imidazol-1-yl)methyl)benzene- $\left.\kappa^{2} \mathrm{~N}^{\prime} \mathrm{N}^{\prime}\right]-$ $\left[\mu_{2}-4,4^{\prime}-\left(\right.\right.$ dimethylsilanediyl)dibenzato- $\left.\kappa^{3} \mathrm{O}, \mathrm{O}^{\prime}: \mathrm{O}^{\prime}\right]$ nickel(II)\}, $\mathrm{C}_{30} \mathrm{H}_{30} \mathrm{~N}_{4} \mathrm{NiO}_{5} \mathrm{Si}$. Z. Kristallogr. New Cryst. Struct., 2017, 232, 121.

29. Davies, R. P.; Less, R.; Lickiss, P. D.; Robertson, K.; White, A. J. P. Structural Diversity in Metal-Organic Frameworks Built from Rigid Tetrahedral $\left[\mathrm{Si}\left(\mathrm{p}-\mathrm{C}_{6} \mathrm{H}_{4} \mathrm{CO}_{2}\right)_{4}\right]^{4-}$ Struts. Cryst. Growth Des., 2010, 10, 4571.

30. Zhang, M.; Chen, Y.-P.; Zhou, H.-C. Structural design of porous coordination networks from tetrahedral building units. CrystEngComm, 2013, 15, 9544

31. Feng, D.; Wang, K.; Wei, Z.; Chen, Y.-P.; Simon, C. M.; Arvapally, R.; Martin, R. L.; Bosch, M.; Liu, T.-F.; Fordham, S.; Yuan, D.; Omary, M. A.; Haranczyk, A.; Smit, B.; Zhou, H.-C., Kinetically tuned dimensional augmentation as a versatile synthetic route towards robust metal-organic frameworks. Nat. Commun., 2014, 5, 5723.

32. Wang, J.; Zhang, J.; Jin, D.; Luo, Y.; Wang, S.; Zhang, Z.; Wu, Y.; Liu, H.; Lu, J. Y.; Fang, M. Synthesis of an exceptional water-stable two-fold interpenetrated $\mathrm{Zn}$ (II)-paddlewheel metal-organic framework. CrystEngComm, 2015, 17, 5906.

33. Gotthardt, J. M.; White, K. F.; Abrahams, B. F.; Ritchie, C.; Boskovic, C. Fluorite Topology in Lanthanoid Coordination Polymers with Di- and Trimetallic Building Blocks. Cryst. Growth Des., 2012, 12,4425 . 
34. Xue, Y.-S.; Zhou, L.; Liu, M.-P.; Liu, S.-M.; Xu, Y.; Xu, Du, H.-B.; You, X.-Z. Construction of lanthanide metal-organic frameworks with highly-connected topology based on a tetrapodal linker. CrystEngComm, 2013, 15, 6229.

35. Li, Y.-X.; Xue, M.; Guo, L.-J.; Huang, L.; Chen, S.-R.; Qiu, S.-L. Syntheses, structures, fluorescence and magnetism of six lanthanide metal-organic frameworks based on silicon-centered tetrahedral ligand. Chem. Res. Chin. Univ., 2013, 29, 196.

36. Li, Y.-X.; Xue, M.; Huang, L.; Chen, S.-R.; Qiu, S.-L. Synthesis, structures, fluorescence and magnetism of two lanthanide metal-organic frameworks with $\mathrm{CaF}_{2}$ topology based on silicon-centered tetrahedral ligand. Chem. Res. Chin. Univ., 2013, 29, 611.

37. Davies, R. P.; Lickiss, P. D.; Robertson, K.; White, A. J. P. $\mathrm{Mg}^{\mathrm{II}}, \mathrm{Ca}^{\mathrm{II}}$, and $\mathrm{Co}^{\mathrm{II}} \mathrm{Metal}^{-O r g a n i c}$ Framework Materials with $\left[\mathrm{Si}\left(\mathrm{p}-\mathrm{C}_{6} \mathrm{H}_{4} \mathrm{CO}_{2}\right)_{3}\left(\mathrm{p}-\mathrm{C}_{6} \mathrm{H}_{4} \mathrm{CO}_{2} \mathrm{H}\right)\right]^{3-}$ Struts. Aust. J. Chem., 2011, 64, 1239.

38. Lee, J. H.; Moon, B.; Kim, T. K.; Jeoung, S.; Moon, H. Thermal conversion of a tailored metal-organic framework into lithium silicate with an unusual morphology for efficient $\mathrm{CO}_{2}$ capture. Dalton Trans., 2015, 44, 15130.

39. Fournier, J. H.; Wang, X.; Wuest, J. D. Derivatives of Tetraphenylmethane and Tetraphenylsilane. Synthesis of New Tetrahedral Building Blocks for Molecular Construction. Can. J. Chem., 2003, 81, 376

40. CrysAlis Pro: Agilent, 2014, Agilent Technologies Ltd, Yarnton, Oxfordshire, UK.

41. Sheldrick, G. M. A short history of SHELX. Acta Crystallogr. Sect. A, 2008, 64, 112.

42. Dolomanov, O. V.; Bourhis, L. J.; Gildea, R. J.; Howard, J. A. K.; Puschmann, H. OLEX2: a complete structure solution, refinement and analysis program. J. Appl. Cryst., 2009, 42, 339.

43. Farrugia, L. J. WinGX and ORTEP for Windows: an update. J. Appl. Cryst., 2012, 45, 849.

44. Duisenberg, A. J. M. Indexing in Single-Crystal Diffractometry with an Obstinate List of Reflections. J. Appl. Cryst., 1992, 25, 92.

45. COLLECT: Data collection software, Hooft, R.; Nonius B.V., 1998, Netherlands.

46. Otwinowski, Z.; Minor, W. Processing of X-ray diffraction data collected in oscillation mode. Methods Enzymol., 1997, 276, 307.

47. SADABS: Version 2007/2, Sheldrick, G. M.; Bruker AXS Inc., 2007, Madison, Wisconsin, USA.

48. Spek, A. L. Single-crystal structure validation with the program PLATON. J. Appl. Cryst., 2003, 36, 7.

49. CrystalMaker: Palmer, D. C.; 2004, CrystalMaker Software Ltd., Begbroke, Oxfordshire, UK.

50. Allen, F. H.; Johnson, O.; Shields, G. P.; Smith, B. R.; Towler, M. CIF applications. XV. enCIFer: a program for viewing, editing and visualizing CIFs. J. Appl. Cryst., 2004, 37, 335.

51. Yin, Q.; Peng, Z.; Sa, R.-J.; Chen, G.-C.; Lü, J.; Liu, T.-F.; Cao, R. An Ultra-Robust and Crystalline Redeemable Hydrogen-Bonded Organic Framework for Synergistic Chemo-Photodynamic Therapy. Angew. Chem. Int. Ed. 2018, 57, doi:10.1002/anie.201800354.

52. Delmas, L. C.; Horton, P. N.; White, A. J. P.; Coles, S. J.; Lickiss, P. D.; Davies, R. P. Siloxane-based linkers in the construction of hydrogen bonded assemblies and porous 3D MOFs. Chem. Commun. 2017, 53, 12524.

53. Hu, F.; Liu, C.; Wu, M.; Pang, J.; Jiang, F.; Yuan, D.; Hong, M. An Ultrastable and Easily Regenerated Hydrogen-Bonded Organic Molecular Framework with Permanent Porosity. Angew. Chem. Int. Ed., 2017, 56, 2101.

54. Schoedel, A.; Li, M.; Li, D.; O’Keeffe, M.; Yaghi, O. M. Structures of Metal-Organic Frameworks with Rod Secondary Building Units. Chem. Rev., 2016, 116, 12466. 
55. Zhao, X.; Shimazu, M. S.; Chen, X.; Bu, X.; Feng, P. Homo-Helical Rod Packing as a Path Toward the Highest Density of Guest-Binding Metal Sites in Metal-Organic Frameworks. Angew. Chem. Int. Ed., 2018, 57, 6208 .

56. Okuniewski, A.; Rosiak, D.; Chojnacki, K.; Becker, B. Coordination polymers and molecular structures among complexes of mercury(II) halides with selected 1-benzoylthioureas. Polyhedron, 2015, 90, 47.

57. White, K. F.; Abrahams, B. F.; Babarao, R.; Dharma, A. D.; Hudson, T. A.; Maynard-Casely, H. E.; Robson, R. A New Structural Family of Gas-Sorbing Coordination Polymers Derived from Phenolic Carboxylic Acids. Chem. Eur. J., 2015, 21, 18057.

58. Shannon, R. D. Revised effective ionic radii and systematic studies of interatomic distances in halides and chalcogenides. Acta Crystallogr. Sect. A, 1976, 32, 751.

59. Alvarez, S. A cartography of the van der Waals territories. Dalton Trans., 2013, 42, 8617.

60. This limit had previously been used when analyzing the $\mathrm{Na}-\mathrm{O}$ interactions in a series of macrocyclic complexes of alkali metal cations. Champion, M. J. D.; Levason, W.; Pugh, D.; Reid, G. Neutral thioether and selenoether macrocyclic coordination to Group 1 cations (Li-Cs) - synthesis, spectroscopic and structural properties. Dalton Trans., 2015, 44, 18748.

61. Addison, A. W.; Rao, T. N.; Reedijk, J.; van Rijn, J.; Verschoor, G. C. Synthesis, structure, and spectroscopic properties of copper(II) compounds containing nitrogen-sulphur donor ligands; the crystal and molecular structure of aqua[1,7-bis(N-methylbenzimidazol-2'-yl)-2,6dithiaheptane]copper(II) perchlorate. J. Chem. Soc., Dalton Trans., 1984, 1349. 
Entry for the Table of Contents

\section{A MOF with a single 3D node}

David Pugh, Emma Ashworth, Karen Robertson, Luke C. Delmas, Andrew J. P. White, Peter N. Horton, Graham J. Tizzard, Simon J. Coles, Paul D. Lickiss* and Robert P. Davies*

Page - Page
The combination of a series of Sicentered linkers with light Group I metals $\left(\mathrm{Li}^{+}\right.$and $\left.\mathrm{Na}^{+}\right)$results in the formation of several new MOFs with interesting structural features. These include a helical chiral node synthesized from achiral starting materials and a novel MOF consisting of a single 3dimensional node. 